\title{
PELVIC LYMPHANEDECTOMY DUE TO METASTATIC BREAST CANCER CAUSING POSTRENAL ACUTE KIDNEY INJURY
}

\author{
Ana Beatriz Charantola Beloni1, Ana Clara Charantola Beloni', Leandro Beloni², Lúcio Fábio Caldas Ferraz \\ ${ }^{1}$ Universidade São Francisco - Bragança Paulista (SP), Brazil. \\ ${ }^{2}$ Hospital Santa Casa de Misericórdia de Tupã - Tupã (SP), Brasil.
}

Introduction: About $30 \%$ of the patients healed from breast cancer recurred with metastasis, and the lymphatic is the main path of dissemination. Usually, postrenal acute kidney failure (AKI) is a result of gynecological, urological, gastrointestinal and retroperitoneal cancer, but unusual in breast cancer. Objectives: To report the unusual metastatic behavior of the carcinoma for diagnostic elucidation. Method: Anamnesis and review of medical charts and bibliography. Results: White, female, 69-year old women being retreated for invasive ductal breast cancer, luminal B type, was hospitalized in June, 2018, with hypothesis of bronchopneumonia and AKI due to dehydration and infection. Laboratory examinations indicated urea at $75 \mathrm{mg} / \mathrm{dl}$, creatinine at $2.56 \mathrm{mg} / \mathrm{dl}$, sodium at $141 \mathrm{mmol} / \mathrm{L}$, and potassium at $4.2 \mathrm{mmol} / \mathrm{L}$. The initial conduct included antibiotics and hydration with $0.9 \%$ saline solution. Abdominal and bladder ultrasound indicated dilatation of the pelvicalyceal systems system and proximal ureters, without pointing a location and cause of obstruction; urinary bladder with conserved shape and capacity; absence of images compatible with calculi and expansive solid, cystic or complex injuries. Due to the worsened glomerular filtration rate and oliguria, a double J catheter was inserted to the left. However, there was no improvement in kidney function. Then, a nephrostomy was performed to the right, which restituted urine traffic. In February, 2019, urotomography showed dilatation of the pelvicalyceal system and right ureters to the pelvis (L5), where it became narrow, with a $1.5 \mathrm{~cm}$ caliber ureter obstruction; multiple metastasis in the pelvic bones and bilateral pleural effusion. A double J catheter was inserted in the right ureter through a cateter via anterograde pathway, thus recovering kidney function and comfort. After 5 months, computed tomography showed pelvic lymphadenopathy as the cause of obstruction. Currently, the patient has a metallic catheter in the right side, with good general status and on anastrozole. Conclusions: Metastatic breast cancer is still challenging and prone to complications. Therefore, its knowledge allows a better approach of patients by correlating them with more diagnostic and care possibilities. 